Occupational therapy and mental disorders (with the College of Occupational Therapists). $£ 2.50$. 1992

Shared care of patients with mental health problems (with the Royal College of General Practitioners). £3.00. 1993
Please send orders, with cheques made payable to the Royal College of Psychiatrists, to the Publications Department at the College. A full list of books published by the College is available on request.

\title{
NHS superannuation regulations
}

The Executive and Finance Committee at the College felt that members of the College should be aware of pending changes in the NHS superannuation regulations. For a considerable amount of time entrants to psychiatry have, if working maximum part-time or full-time and devoting the majority of their clinical sessions to clinical psychiatry, been eligible for Mental Health Officer status. The implications of this are that after 20 years of Mental Health Officer status superannuation contributions count double and there is the ability to retire at $\mathbf{5 5}$, effectively meaning that after 32.5 years, 45 years of contributions will have been accrued. The changes pending in the superannuation regulations which, sad to say, have been negotiated by the British Medical Association, are that Mental Health Officer status will be lost for new entrants to psychiatry, although existing holders of Mental Health Officer status will continue to keep that. The reason for this loss is an agreement with government to improve pension arrangements across the whole medical profession. The government insisted that this should be self-financing and the cost that they sought was the abolition of Mental Health Officer status and the BMA agreed to this. So, for people currently working in psychiatry who have not yet applied for Mental Health Officer status do it now and for those who feel strongly about it, you might wish to write to the BMA.

While the College does not wish to get involved in terms and conditions of service for psychiatrists, this being a matter for the British Medical Association, it is felt the loss of Mental Health Officer status may well affect recruitment into psychiatry and indeed given the current pressures within the NHS it might be that similar arrangements should work for more doctors rather than doing away with it for psychiatrists.

M.J. HARRIS, Sub Dean, Royal College of Psychiatrists 